\title{
HISTOLOGIA GERAL DOS INTESTINOS DO CAIMAN CROCODILUS YACARE (DAUDIN, 1802) (CROCODILIA:REPTILIA)
}

\author{
Sonia Maria Jin ${ }^{1}$ \\ Sandra Maria das Graças Maruch ${ }^{2}$ \\ Marco Aurélio Martins Rodrigues ${ }^{1}$ \\ Paula Pacheco ${ }^{3}$
}

\begin{abstract}
General histology of small intestine (duodenum and jejunum) and the large intestine (colon and cloaca) of C. c. yacare (Daudin, 1802) Crocodilia-Reptilia. A comparative description is made of the histology of the small and large intestine of $\mathrm{C}$. $\mathrm{c}$. yacare. In all segments mucosa, submucosa, muscularis and serosa tunics were observed. The duodenum as very long villi, wich are well-developed and at tached together to form irregular transverse ridges, covered with simple columnar epithelium with marginal and goblet cells. In the jejunum, the villi are shorter and less frequent. The colon as few folds, covered with the same epithelium; the lamina propria contains straight tubular glands with absortive cells, goblet and Paneth cells. The cloaca is very complex, with three well-defined regions: coprodeum, urodeum and proctodeum. In the coprodeum, the wall is folded, less muscular and the thin mucosa is covered by an epithelium with a few basal cells and mucosal cells. The urodeum as an additional external muscular tunic, with striated muscle fibers and a stritifield cylindrical epithelium with goblet cells. The proctodeum includes the free part of the penis in the male and, laterally, the ducts of a pair of holocrine cloacal glands. Near the opening of the ducts, the epithelium changes to a squamous keratinized type.
\end{abstract}

\section{INTRODUÇÃO}

Os primeiros estudos de JACOBSHAGEN (1920), relatam uma variedade notável nos aspectos morfológicos dos intestinos de répteis, não só quando se considera o relevo interno (JACOBSHAGEN, 1937) como os aspectos histológicos (VIALLI, 1929; REISS \& LYONS, 1943; TÖRÖ, 1930; LUDWIG \& RICHTERICH, 1954). A maioria dos trabalhos, entretanto, se refere a estudos histológicos sobre intestinos de cobras (MORI, 1935; GABE \& SAINT-GIRONS, 1972), lagartos (BAECKER, 1934; PARSONS \&CAMERON, 1977) e tartarugas (LUPPA, 1977). Os crocodilianos são, com exceção das aves, os únicos animais viventes diretamente relacionados aos grandes dinossauros, pois compartilharam um ancestral comum no final do Triássico (TAGUCHI, 1920). Apesar dessa posição estratégica dentro da filogenia dos répteis, os estudos sobre o intestino dos crocodilianos, são escassos (TÖRO, 1930; YAMADA et al., 1987) e a distribuição dos vários tipos celulares varia consideravelmente entre as espécies (GABE \& SAINT-GIRONS, 1972; GABE, 1971).

1. Depto. de Morfofisiologia, Universidade Federal de Mato Grosso do Sul, Cx. Postal 649, Campo Grande, MS, CEP 79069.

2. Depto. de Morfologia, Universidade Federal de Minas Gerais, Belo Horizonte, MG.

3. Bolsista de Iniciação Científica, Universidade Federal de Mato Grosso do Sul. 
Este trabalho apresenta a histologia geral dos intestinos do Caiman crocodilus yacare, com o objetivo de contribuir para conhecimento deste órgão nessa espécie, possibilitando estudos comparativos posteriores.

\section{MATERIAL E MÉTODOS}

Para o desenvolvimento deste trabalho foram utilizados quatro jacarés Caiman crocodilus yacare, de ambos os sexos, coletados na região do pantanal de Mato Grosso do Sul. Os animais foram anestesiados por inalação de éter, os intestinos dissecados e os fragmentos fixados em Bouin, desidratados, diafanizados e incluídos em parafina. Cortes seriados foram obtidos em 3-5 $\mu \mathrm{m}$ e submetidos aos seguintes métodos de coloração: H.E., tricrômico de Gomori para fibras colágenas, fucsina-resorcina para fibras elásticas, tricrômico de Gomori para fibras reticulares, PAS e alcian-blue (LUNA, 1960; BEHMER et al., 1976). As lâminas foram analisadas e fotomicrografadas em fotomicroscópio Zeiss III.

\section{RESULTADOS}

\section{a) Intestino delgado}

$\mathrm{O}$ intestino delgado compreende um segmento proximal à válvula pilórica; o duodeno e um segmento distal; o jejuno-íleo limitado caudalmente por um esfíncter. O duodeno termina no ponto de origem do mesentério e forma uma alça que abriga um pâncreas bem organizado. O seu relevo interno apresenta inúmeras vilosidades, dispostas em linhas paralelas e transversais, que se conectam em vários pontos, possuem extremida. des livres e pequenas projeções laterais (Fig. 1A). A altura, freqüência e tamanho das vilosidades diminuem à medida que se afastam da válvula pilórica e no jejuno-1leo são baixas e espaçadas. No intestino delgado estão presentes todas as túnicas, porém a submucosa é muito estreita (Fig. 1A). Apesar disso é perfeitamente observável o plexo submucoso descrito para outros répteis. No duodeno a túnica mais desenvolvida é a mucosa enquanto no jejuno-1́leo a mais espessa é a túnica muscular (Fig. 1B). As vilosidades são estruturas cônicas, constituídas de tecido conjuntivo frouxo do córion, revestidas por epitélio. Em seu eixo podem ser observadas fibras musculares lisas projetadas pela muscular da mucosa, um quilífero central e capilares sangüíneos. Há uma grande infiltração linfocitária na lâmina própria e no epitélio, assim como inúmeras figuras mitóticas. O epitélio de revestimento é cilindrico simples com células absortivas e células caliciformes. As células absortivas possuem borda estriada, núcleo oval de posição basal com um a dois nucléolos. O citoplasma apresenta uma área perinuclear fracamente acidófila e outra área apical corável mais fortemente pela eosina. A célula caliciforme é estreita com núcleo semelhante ao da célula absortiva e seu citoplasma é fortemente PAS e alcian-blue positivos (Figs. 1C e 1D). A muscular da mucosa é dupla, com camada interna de fibras musculares lisas circulares e camada externa de fibras longitudinais. Após uma delgada submucosa observa-se a túnica muscular espessa com camada interna de fibras musculares lisas circulares e camada externa de fibras longitudinais. Essa última é pelo menos cinco vezes mais delgada e entre as duas observa-se o plexo mioentérico. A serosa é delgada e constituída de conjuntivo frouxo e mesotélio. Não há glândulas intestinais bem desenvolvidas. Apenas em regiões mais ricas em vilosidades como a porção cranial do duodeno, é que se poderiam caracterizar estruturas semelhantes às criptas de 
Vol. 7(1-2), 1990

Lieberkühn (glândulas intestinais), porém pouco desenvolvidas, no córion de alguns cortes (Fig. 1A). Não são observadas também glândulas semelhantes às de Brünner ou quaisquer outras descritas para mamíferos.

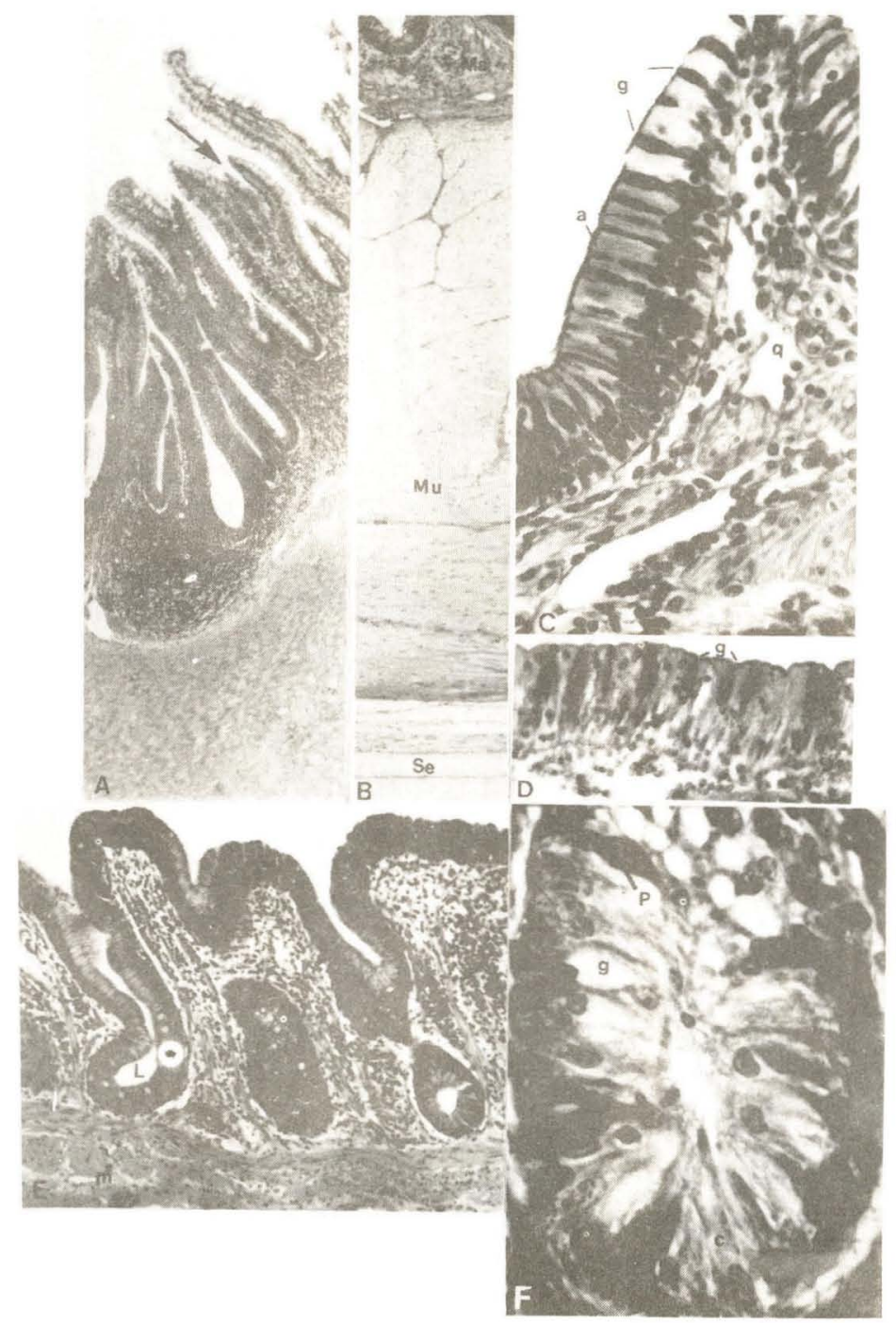

Fig. 1 - Fotomicrografias de cortes transversais do intestino do C. c. yacare. Evidenciando em: $A$ : vilosidades duodenais altas com ramificaçōes laterais (seta) H.E. 20X. B: as túnicas gerais: Ma - mucosa; Su - Submucosa; Mu - muscular;Se - serosa;PAS: 16X. C: o epitélio de revestimento com: células absortivas (a); células caliciformes $(\mathrm{g})$ e quilífero central (q) PAS 20X. D: células caliciformes $(\mathrm{g})$ alcian-blue positivas; alcian-blue $20 \mathrm{X}$. E: a mucosa do colon com glândulas intestinais (L) e muscular da mucosa (m) H.E. 20X. F: o fundo da glândula intestinal com células caliciformes (g), células cilíndricas (c) e células de Paneth (p). T. Gomori, $40 \mathrm{X}$. 

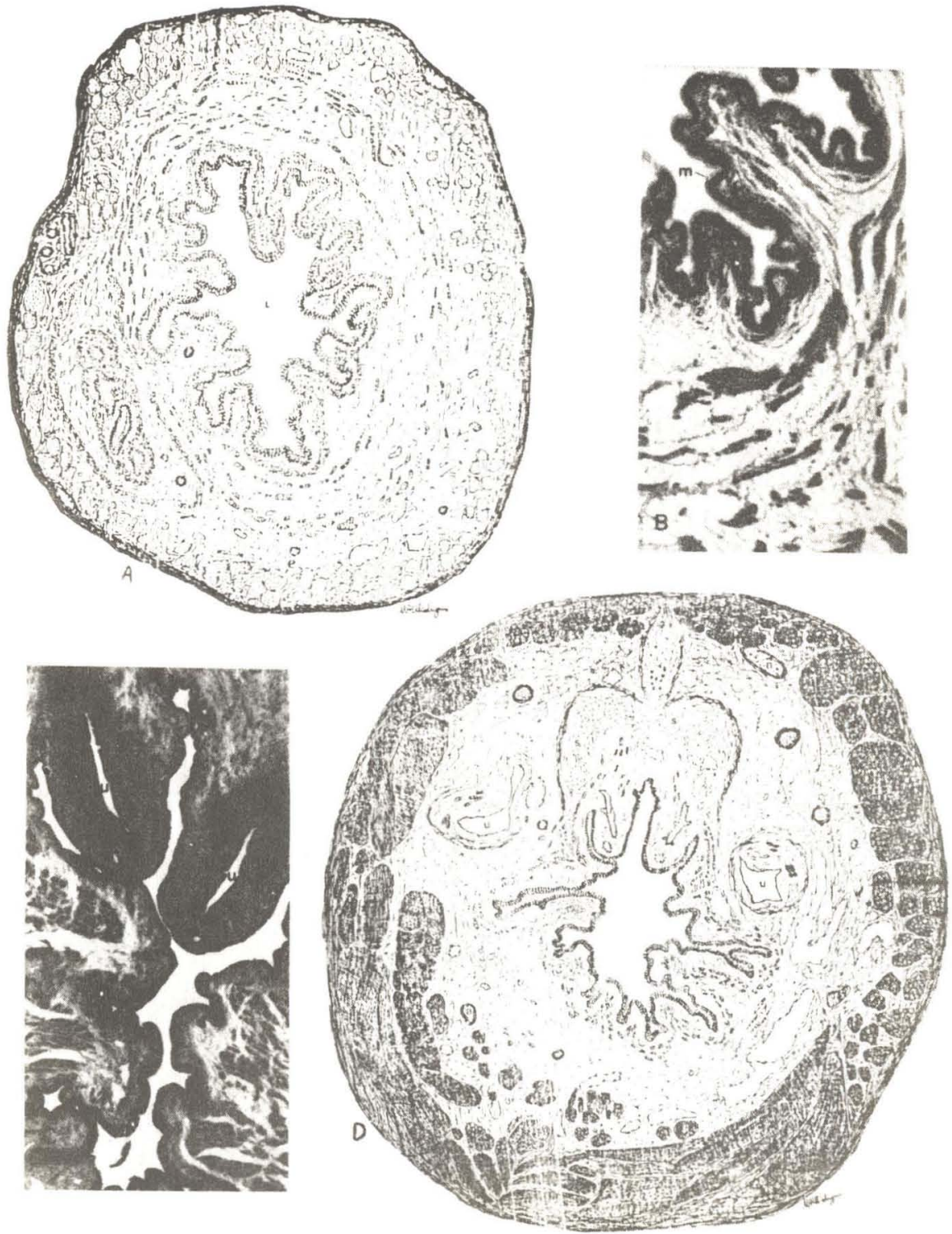

Fig. 2 - Fotomicrografias e esquemas gerais de segmentos da cloaca evidenciando em a: aspecto geral do coprodeum com a luz coacal (L), a persistência da muscular da mucosa; a camada interna (i) e a camada externa (e) da túnica muscular. B: as pregas do coprodeum com epitélio rico em células mucosas (m). C: a desembocadura dos ureteres (u) na parede do urodeum. D: aspecto geral da parede do urodeum com abertura dos ureteres (u), seios venosos (s), artéria distribuidora (a), nervo (n), a camada interna de fibras musculares lisas (L) e camada externa de fibras musculares estriadas esqueléticas (E). 


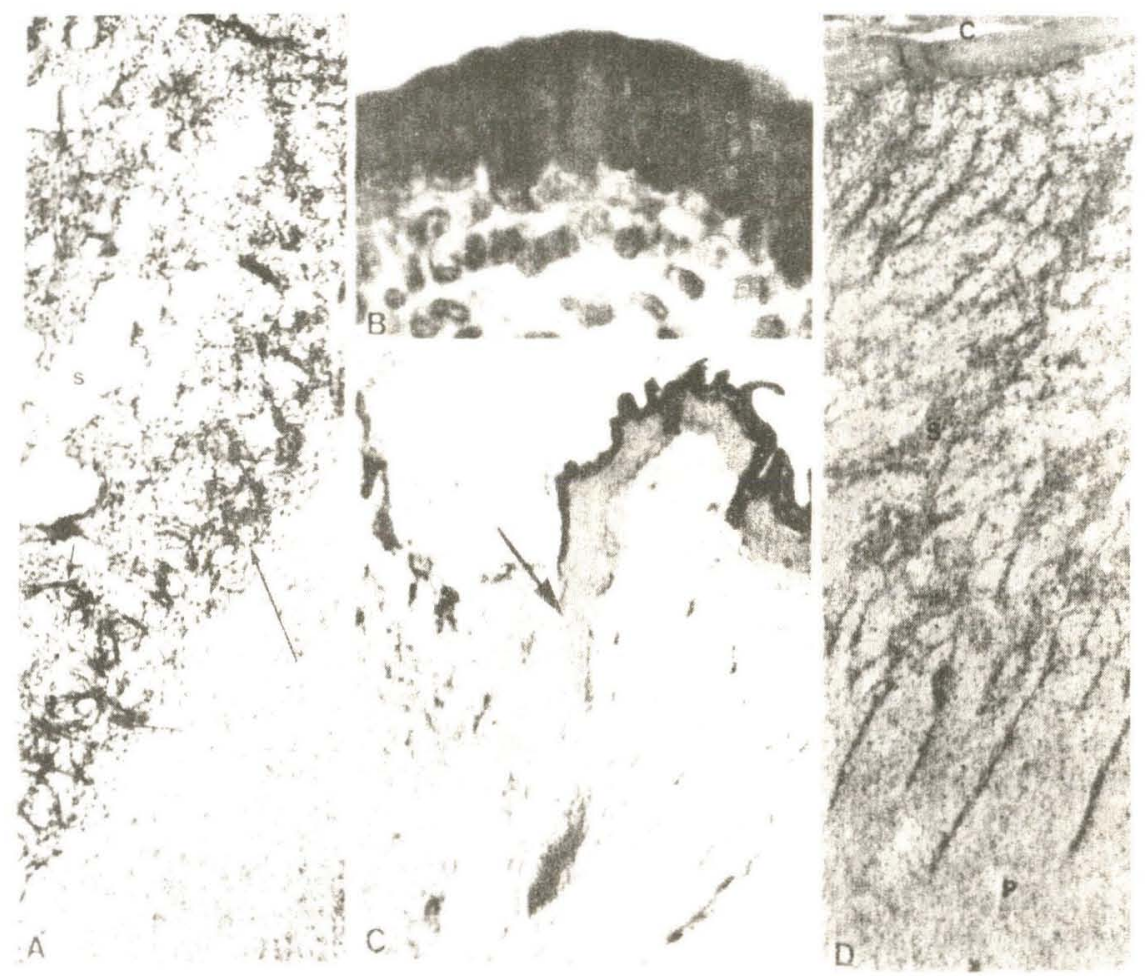

Fig. 3 - Fotomicrugrafias de cortes transversais da cloaca do C. c. yacare evidenciando em A : a riqueza de fibras reticulares (seta) ao redor dos seios venosos (s) reticulina de Gomori 20X. B: o epitélio de revestimento do urodeum com células basais e células globosas PAS positivas. PAS 60X. C: a transição entre a parede glandular das glândulas cloacais e o início do ducto excretor (seta). t. Gomori 20 X. D: a parede da glândula cloacal com cápsula (C), septos conjuntivos (S) e parênquima secretor (P) HE 20X.

b) Intestino grosso (cólon e cloaca)

O intestino grosso se apresenta logo após uma constricção abrupta da parede do intestino delgado e compreende cólon e cloaca. Nessa constricção há um espessamento muscular sugerindo a presença de um esfíncter. As paredes internas são lisas podendo apresentar pregas. O cólon é um segmento curto correspondendo aproximadamente à décima parte do comprimento total do intestino. Na sua porção distal sofre um outro estrangulamento com um novo esfíncter que dá acesso à cloaca. A mucosa é revestida por 
epitélio cilíndrico simples com células absortivas e células caliciformes. Estão presentes, na lâmina própria, glândulas de Lieberkühn (Fig. 1E). A distribuição destas estruturas entretanto, não é homogênea, havendo áreas onde elas não ocorrem. O epitélio de revestimento e as glândulas de Lieberkühn apresentam células cilíndricas, células caliciformes e células de Paneth (Fig. 1F). As células cilindricas e caliciformes apresentam o mesmo aspecto e positividade para PAS e alcian-blue que no intestino delgado, porém as caliciformes aumentam muito em número. As células de Paneth são poliédricas, de núcleo esférico, citoplasma repleto de grânulos acidófilos e localizam-se, preferencialmente, no fundo da glândula intestinal (Fig. 1F). A muscular da mucosa apresenta-se espessada e constituída de três camadas de fibras musculares lisas. Emite pequenos septos para dentro do córion, que ladeiam as glândulas de Lieberkühn. A túnica muscular é a mais espessa das túnicas. No cólon está acrescida de uma camada de fibras que não é observada em outros segmentos intestinais. O conjuntivo da submucosa lâmina própria, assim como aquele que envolve fascículos e fibras musculares é rico em fibras reticulares e possuem uma pequena quantidade de fibras elásticas.

A cloaca corresponde aproximadamente a um terço do comprimento total do cólon. Seu diâmetro é ligeiramente menor, suas paredes espessadas e sua estrutura muito complexa, tanto do ponto de vista macroscópico quanto histológico. O segmento inicial é precedido por uma constricção do cólon e pregas longitudinais que marcam o coprodeum. Em seguida observam-se os orifícios terminais dos ureteres na região dorsal, caracterizando o urodeum. Após esse, há uma prega anular espessada que dá acesso ao proctodeum. O proctodeum inclui a parte livre do pênis nos machos e lateralmente os ductos de um par de glândulas cloacais. A abertura da cloaca é uma fenda longitudinal revestida exteriormente pelo tegumento.

A nível de cloaca as túnicas gerais descritas para o restante do tracto digestório não apresentam a mesma organização. No coprodeum a mucosa pregueada é revestida por epitélio constituído de uma camada de células basais, células cilíndricas e células globosas. Tais células são mais desenvolvidas que as já descritas e seus citoplasmas apresentam respostas histoquímicas semelhantes às do cólon e intestino delgado. A muscular da mucosa, de fibras circulares, está incluída nas pregas. A área de conjuntivo frouxo expande-se e a muscular se distribui em fascículos. Abaixo da submucosa a camada interna da túnica muscular está bem reduzida e suas fibras são circulares. A camada externa se restringe a fascículos de fibras longitudinais (Figs. 2A e 2B). No urodeum, entretanto, a complexidade da parede cresce muito (Figs. 2C, 2D, 3A e 3B). As pregas da mucosa apresentam um epitélio estratificado com células caliciformes, e em duas pregas dorsais desembocam os ureteres. O epitélio de revestimento destes ductos é cilíndrico a cúbico simples e a sua luz é irregular. Na região dessas duas pregas dorsais define-se um fascículo de musculatura lisa ao redor do qual se observa espaços, de luz irregular, revestidos por endotélio, preenchidos por células sangüineas, semelhantes a seios venosos de tecido erétil. Estes seios venosos constituem duas massas de tecido bem desenvolvidas dispostas lateroinferiormente às pregas dorsais e distribuídos em torno da luz cloacal. Externamente à submucosa, na região anterior, aparecem volumosos fascículos de fibras muscu. lares lisas e perifericamente a eles, uma camada espessa de fibras musculares estriadas esqueléticas que envolve todo o urodeum. O proctodeum apresenta a mesma histologia básica, porém o epitélio torna-se estratificado pavimentoso queratinizado próximo à abertura dos ductos das glândulas cloacais. Estas glândulas são pares, bem desenvolvidas, exócrinas, simples, acinosas e holócrinas. O seu parênquima é constituído de enormes células poliédricas produtoras de abundante secreção amarelada (Figs. 3C e 3D). 


\section{DISCUSSÃO E CONCLUSÕES}

Desde a monografia de OPPELL (1900) que se afirma que não há vilosidades no intestino de répteis. No entanto, REISS \& LYONS (1943) descreveram várias estruturas no revestimento como pregas. VIALLI (1929) descreveu uma ampola cólica nos iguanídeos e uma prega espiral no gênero Trionix (tartaruga) e NICHOLAS (1891) descreveu vilos na mucosa de Python bivittatus. PARSONS \& CAMERON (1977), descreveram pregas longitudinais e transversais no intestino de vários ofídios. Entretanto, admitem a presença de estruturas viliformes no gênero Typhlops e Mascophis. Esses achados confirmam as observações de vilos no duodeno de Tuphops lineatus, onde poderiam estar ligados por pregas transversais e longitudinais, JACOBSHAGEN (1920). Para alguns autores, na ordem Crocodilia, o intestino delgado apresenta pregas em zig-zag longitudinais e transversais complicadas com protuberâncias e irregularidades, porém não se referem a vilos JACOBSHAGEN (1920), PARSONS \& CAMERON (1977). No C. c. yacare o duodeno apresenta vilosidades cônicas dispostas em fileiras longitudinais e transversais. Estas vilosidades se conectam em alguns pontos, mas suas extremidades são livres. Apresentam também pequenas projeções livres lateralmente. Estas vilosidades apresentam um eixo de tecido conjuntivo percorrido por algumas fibras musculares lisas, capilares sangüíneos e quilífero central. As fibras musculares, semelhantes ao músculo de Brücke descrito para vilosidades intestinais de mamíferos, são emitidas a partir da muscular da mucosa e estão presentes também nas projeçôes laterais. Assim, histologicamente, esses vilos possuem todas as estruturas descritas para os mamíferos, não havendo razão para nomeá-los de outra maneira.

As investigações de TÖRÖ (1930) descrevem criptas intestinais no intestino delgado dos crocodilianos, tartarugas e lagartos. LUPPA (1977) descreveu estas estruturas em alguns lagartos e tartarugas VIALLI (1929) e REISS \& LYONS (1943) as consideram ausentes nas cobras. Nós observamos que no $C$. $c$. yacare não há glândulas de Lieberkühn no intestino delgado porém são bem caracterizadas no cólon e não aparecem na cloaca. 0 epitélio de revestimento e das criptas possuem os mesmos tipos celulares descritos para aves e mamíferos. As células absortivas no $C$. c. yacare, descritas como células marginais por vários autores em intestino de outros répteis (LUDWIG \& RICHTERICH, 1954; PARSONS \& CAMERON, 1977; LUPPA, 1977), possuem borda estriada, zona granular, zona clara e zona de mitocôndria. A morfologia geral é basicamente a mesma descrita para o intestino de mamíferos (PATZELT, 1930). As células caliciformes ou globosas, estão entre as células absortivas e foram muito bem caracterizadas por VIALLI (1929). A região supranuclear do citoplasma está preenchida com muco ou seus precursores e apresenta-se PAS e alcian-blue positivos. O citoplasma circundante ao núcleo se cora mais fortemente que o restante. Esses achados confirmam os resultados de GABE \& SAINT-GIRONS (1972) para outros répteis.

No C. c. yacare observamos que, semelhantemente ao que ocorre nas cobras GABE \& SAINT-GIRONS (1972), o número de células caliciformes é maior no cólon e cloaca que no intestino delgado. Não foram observadas células de Paneth no intestino delgado e cloaca, porém elas estão presentes no cólon. Sua posição é a mesma descrita por BAECKER (1934) e HINTZSCHE \& ANDEREG (1938), no fundo da cripta de Lieberkühn. TAGUCHI (1920) relatou que nos crocodilianos estudados por ele (Crocodilus niloticus, Crocodilus porosus, Alligator sinensis) as células de Paneth estão em todas as regiôes intestinais. Porém estes dados são conflitantes com os de TÖRÖ (1930). 
No C. c. yacare só observamos este tipo celular no cólon. Entretanto, essas diferenças de resultados podem ser devidas a inclusão de ácido acético na solução fixadora, pois BAECKER (1934) sugere que os grânulos podem ser dissolvidos por essas soluções. As células de Paneth do intestino reptiliano são fundamentalmente similares às de outros vertebrados. TAGUCHI (1920) afirma que em Crocodylus o cólon tem uma parede mais espessa que o intestino delgado, enquanto que na espécie que estudamos a parede do cólon é menos espessa que a do intestino delgado. Criptas intestinais bem desenvolvidas foram descritas para Sphenodon (OSAWA, 1897), porém GRESCHIK (1917) descreveu depressões semelhantes às criptas apenas em Anguis fragilis. Glândulas de Lieberkühn foram observadas em Emys (MACHATE, 1879), Ophiscurus apodus (PATZELT, 1930) e Chamaleo dileps (ESCH, 1936). No cólon do C. c. yacare ocorre uma melhor definição das glândulas de Lieberkühn que se apresentam tubulosas retas, constituídas de células absortivas, células caliciformes e células de Paneth. No jejuno elas não aparecem e no duodeno somente quando há proximidade excessiva das vilosidades é que se delineam estruturas comparáveis às criptas, mas que podem ser interpretadas também como intervalos laterais afastados das vilosidades. Outra particularidade do cólon, não referida na revisão de LUPPA (1977) é o espessamento da túnica muscular que ganha uma camada de fibras longitudinais semelhantemente ao que ocorre nas tênias do cólon descritas para mamíferos. No $C$. c. yacare não está presente um ceco dorsal descrito para outros répteis (LUPPA, 1977).

Desde as investigações clássicas de GERHARDT (1937) que ficou demonstrada a grande complexidade da cloaca dos répteis. GABE \& SAINT-GIRONS (1965) divulgaram resultados sobre anatomia, histologia e histoquímica de várias espécies de répteis e WHITING (1969) enriqueceu este acervo descrevendo outras espécies. LUPPA (1977) refere-se a esta complexidade, porém se detém mais na discussão dos tipos celulares do epitélio que propriamente na estrutura histológica geral do segmento cloacal. Na cloaca do $C$. c. yacare modifica-se fundamentalmente a organização geral do tracto. Essa variação é notável e característica para cada um dos segmentos, pelo menos nos machos.

Os tipos celulares do epitélio de revestimento são os mesmos descritos em Lacerta, Emys, Testudo graeca e outros répteis (GABE, 1971; LUPPA, 1977). Porém os trabalhos referidos, não consideram os vários segmentos cloacais em suas descrições. Segundo GABE \& SAINT-GIRONS (1972) há dois tipos de glândulas cloacais nos répties: as glândulas urodeais com uma única cripta epitelial e as glândulas cloacais, anatomicamente limitadas. No $C$. c. yacare não observamos as primeiras, mas enormes glândulas ovais, lobuladas entre o conjuntivo subepitelial e a camada muscular. Vários autores descreveram glândulas lobulares, holócrinas em crocodilianos (RIEKEN \& PEARSE, 1966; VOELTSKOW, 1902; DISSELHORST, 1904; TAGUCHI, 1920; BAKER, 1942). Parece que essas glândulas estão relacionadas com a maturidade e estimulação sexual. Nossas observações histológicas, feitas principalmente em machos, não nos permitem avaliar esta informação. A análise histológica, entretanto, nos mostra que a secreção é holócrina, as células secretoras são prismáticas, volumosas, de citoplasma vacuolizado e acidófilo e de núcleo esférico e central. Além disso, podemos observar que a parte mais interna, próxima à parede, apresenta pequenos cordões celulares, sustentados por conjuntivo, ladeados por capilares semelhantes a porções granulares cordonais de função endócrina. Entretanto essas observações carecem de estudos posteriores. 


\section{AGRADECIMENTOS}

Os autores agradecem ao CNPq, IBAMA, PROPP(UFMS) pelo apoio recebido.

\section{REFERÊNCIAS BIBLIOGRÁFICAS}

BAECKER, R. 1934. Die oxyphilen Panethschen Kornchenzellen im Darmephithel der Wirbeltiere. Erg. Anat., 31: 708-755.

BAKER, J.R. 1942. The free border of the intestinal epithelial cell of vertebrates. Quart. J. Micr. Sci., 84: 73-103.

BEHMER, O.A.; E.M.C. TOLOSA \& A.G.F. NETO, 1976. Manual de técnicas para histologia normal e patológica. São Paulo, Editora da Universidade de São Paulo. 254 pp.

DISSELHORST, R., 1904. Mannliche Geschlechtsorgane. Reptilien. In: Oppels Lehrbuch der Vergleichenden Mikroskopischen Anatomie der Wirbelterre, 4:60-89.

ESCH, H., 1936. Eigentümliche Reliefbildungen der tiefen Wandschichten im Enddarm der Saurier, ihre Entstehung und Bedeutung. Anat. Anz., 82: 162-190.

GABE. M., 1971. Répartition des cellules histaminergiques dans la parvis gastrique de quelquer reptiles. C. R. Acad. Sci., Paris, 273: 2287-2289.

GABE; M. \& H. SAINT-GIRONS. 1965. Contribution à la morphologie comparée du cloaque et des glandes épidermioides de la région cloacale chez les lépidosauries. Mem. Mus. Hist. Nat., Paris, 4 (A33): 149-292.

GABE, M. \& H. SAINT-GIRONS. 1972. Contribution al'histologie de L'estomac des lépidossauriens (Reptilis). Zool. Jb., 89:572-599.

GERHART, U. 1937. Kloake und begattunsorgane. In: Handbuch der Vergleichenden Anatomie der Wirbeltiere. (L. Bolk. E. Goppert, E. Kallius and Lubosch, eds.), 6: 267-350, Urban und Schwarzenberg, Berlin an Wien.

GRESCHIK, E. 1917. Uber den Karmkanal von Ablepharus pannonicus Fitz, und Anguis fragilis L. Anat. Anz., 50: 70-80.

HINTZSCHE, E. \& P. ANDEREG, 1938. Histophysiologishe Studien an den Panethschen Zellen. Z. Mikr-Anat. Forsh, 43: 143-152.

JACOBSHAGEN, E. 1920. Zur morphologie, des oberflächen reliefs der rumpf dar muschleimhaut der reptielien. Zena Z. Naturw., 56: 361-430.

JACOBSHAGEN, E. 1937. Handbuch der vergleichenden Anatomie der Wierbeltiere. Urban und Schwarzenberg, Berlin and Wien, vol. 3:563-724.

LUDWIG, E. \& R. RICHTERICH, 1954. Morphologische und histochemische Untersuchungen am Stäbschensaum der Darmephthelzelle. Acta Anat., 21:168-196.

LUNA, L.G., 1960. Hstologic staining methods of the Armed Forces Institute of Pathology. 3. ed. New York, Mc-Graw Hill, 1960.

LUPPA, H., 1977. Histology of the digestive tract. In: Gans, C., ed. Biology of the Reptilia. London, Academic Press, v. 6, p. 225-313.

MACHATE, J., 1879. Untersuchungen "uber feineren Bau des Darmkanats von Emys europeae. Z. Zool., 32: 443-459.

MORI, K. 1935. Die acidophilkörnten Becherzellen als eine Art der Panethschen Zelle. NagasakiIgakkwai - Zassi (Jap), 13: 1060-1065.

NICHOLAS, A., 1891. Rechersche su l'épithélium de I'intestin grêle. Internat. Mschr. Anat. Physiol. 8: $1-58$.

OPPELL. A, 1900. Lehrbuch der vergleichenden mikroskopischen anatomie der Wirbeltiere. Jena, Gustav Fischer, v. 3.

OSAWA, G. 1897. Beitr"age sur Lehre von den Einge Weidein der Hatteria punctata. Arch. Mikr. Anat., 49: 113-226.

PARSONS, TS. \& J.E. CAMERON, 1977. Internal Relief of the Digestive Tract. In: Biology of Reptilia. ed. By,Carl Gans. Academic Press, London and New York, vol. 6: 159-224.

PATZELT, V. 1930. Uber die erste Entwicklung der Zotten im menschlichen Darm und ihre Beteilingung an der Bildung der Krypten. Verh. Anat. Ges., 71: 95-107.

REISS, R.H. \& W.: LYONS, 1943. Histology of the small and large intestine of the common green snake. Thamanophus sirtalis. I. Duodenum, Wasmann Collect., 5 (3): 81-88.

RIEKEN, E.O. \& A.G.E. PEARSE, 1966. Histochemical study on the Paneth cell in the rat. Gut., 7:86-93. 
TAGUCHI, H., 1920. Beiträge zur Kenntnis über die feinere Shuktur der Eingeweideorgane der Krokodile. Milt. Med. Fak., Tokio, 25: 119-188.

TÖRÖ, E., 1930. Zur Frage der Darmresorption auf Grund von Untersuchungen am Krokodildarm. Z. Mild.-Anat. Forschi. 19:537-556.

VIALLI, M., 1929. Richerche sull intestino dei Rettili. 1. Il tratto ileociecocolico. Arch. Ital. Anat., 26: 454-492.

VOELTSKOW, R., 1902. Beiträge zur Entwicklungsgeschichte der Reptilien. Biologie und Entwicklung der äuberen Körperformen von Crocodylus madagascariensis Grand Abh. Senckenb. Naturf. Ges., 26: 13-16.

WHITING, A.M., 1969. Squamate cloacal glands: morphology, histology and histochemistry. Thesis: Pennsylvania State University.

YAMADA, J.; V.J.M., CAMPOS; N. KITAMURA; A. PACHECO; T. YAMASHITA \& N. YABAUHARA, 1987. An imunohistochemical study of the endocrine cells in the grastrointestinal mucosa of the Caiman latirostris. Archivum Histologicum Japonicum, 50 (2): 229-241. 